\title{
Electro-physical properties of jute fabrics in a condition of high humidity - Effect of fabric chemical composition and coating with Cu-based nanoparticles
}

\author{
Aleksandra Mirce Ivanovska ( $\nabla$ aivanovska@tmf.bg.ac.rs ) \\ University of Belgrade, Innovation Center of the Faculty of Technology and Metallurgy \\ https://orcid.org/0000-0001-6846-9583 \\ Slavica Maletić \\ University of Belgrade, Faculty of Physics

\section{Veljko Djokić} \\ University of Belgrade, Innovation Center of the Faculty of Technology and Metallurgy \\ Nenad Tadić \\ University of Belgrade, Faculty of Physics \\ Mirjana Kostić \\ University of Belgrade, Faculty of Technology and Metallurgy
}

\section{Research Article}

Keywords: jute, electro-physical properties, dielectric loss tangent, effective relative dielectric permeability, high humidity, Cu-based nanoparticles

Posted Date: March 13th, 2021

DOI: https://doi.org/10.21203/rs.3.rs-286786/v1

License: (c) (i) This work is licensed under a Creative Commons Attribution 4.0 International License. Read Full License 


\section{Electro-physical properties of jute fabrics in a}

2 condition of high humidity - Effect of fabric

3 chemical composition and coating with $\mathrm{Cu}-$

4 based nanoparticles

5 Aleksandra Ivanovska ${ }^{1, *}$, Slavica Maletić ${ }^{2}, V$ Veljko Djokić ${ }^{1}$, Nenad Tadić$^{2}$, Mirjana

6 Kostić $^{3}$

$7 \quad{ }^{1}$ University of Belgrade, Innovation Center of the Faculty of Technology and

8 Metallurgy, Karnegijeva 4, 11000 Belgrade, Serbia

$9{ }^{2}$ University of Belgrade, Faculty of Physics, Studentski Trg 12, 11000 Belgrade,

10 Serbia

$11{ }^{3}$ University of Belgrade, Faculty of Technology and Metallurgy, Karnegijeva 4,

1211000 Belgrade, Serbia

14 Corresponding authors:

15 e-mail: aivanovska@tmf.bg.ac.rs, tel: +381 11 3303628, ORCID: 0000-0001-6846-9583

16 e-mail: kostic@tmf.bg.ac.rs, tel: +381 11 3303628, ORCID: 0000-0001-9925-4884

18 Funding

19 This work was supported by the Ministry of Education, Science and Technological Development

20 of the Republic of Serbia (Contract No. 451-03-68/2020-14/200135 and 451-03-68/2020-

21 14/200162).

23 Conflicts of interest: The authors declare that they have no conflict of interest.

Author contributions:

Conceptualization: [A. Ivanovska]; Methodology: [A. Ivanovska]; Formal analysis and investigation: [A. Ivanovska], [S. Maletić], [V. Djokić], [N. Tadić]; Writing - original draft preparation: [A. Ivanovska]; Review and editing: [S. Maletić], [V. Djokić], [N. Tadić], [M. Kostić];

29 Supervision: [M. Kostić].

31 Abstract

32 The electro-physical properties of raw and chemically modified jute fabrics were studied as

33 complex phenomena of the interaction between the fabrics' chemical composition, crystallinity, 
moisture sorption, $\mathrm{COOH}$ group content, structural characteristics, and frequency of the electric

35 field. At $80 \%$ relative air humidity, all chemically modified jute fabrics have $38-179 \%$ and 1.7-5.4

36 times higher dielectric loss tangent and effective relative dielectric permeability compared to

37 unmodified, respectively. To further improve these properties, fabrics were treated with $\mathrm{CuSO}_{4}$

38 and Cu-based nanoparticles were in situ synthesized on their surface by reduction. A few single

39 Cu-based nanoparticles were observed across the alkali modified fabric's surface, while single and

40 agglomerated nanoparticles were distributed over the oxidatively modified fabric's surface. No

41 matter whether metallic $\mathrm{Cu}$ or copper oxide $\left(\mathrm{Cu}_{2} \mathrm{O}\right.$ or $\left.\mathrm{CuO}\right)$ nanostructures (or their mixtures) are

42 synthesized (proven by XRD), excellent fabrics' effective relative dielectric permeability is

43 guaranteed. In other words, during the exploitation in specific conditions contributing to copper

44 reduction, the jute fabrics will be able to store 21-163 times more energy from an external electric

45 field than before the exploitation, which further extended their lifetime. On the other hand, with

46 increasing the total content of $\mathrm{Cu}$ after the reduction and formation of single and agglomerated $\mathrm{Cu}$ -

47 based nanoparticles, the movement of jute structural components' molecules becomes difficult

48 resulting in lower energy dissipation within the chemically modified than within unmodified

49 fabric. Applied chemical modification and coating with Cu-based nanoparticles enables designing

50 fabrics with predictable electro-physical properties, which is very important from the application

51 point of view.

52 Keywords: jute, electro-physical properties, dielectric loss tangent, effective

53 relative dielectric permeability, high humidity, $\mathrm{Cu}$-based nanoparticles

54
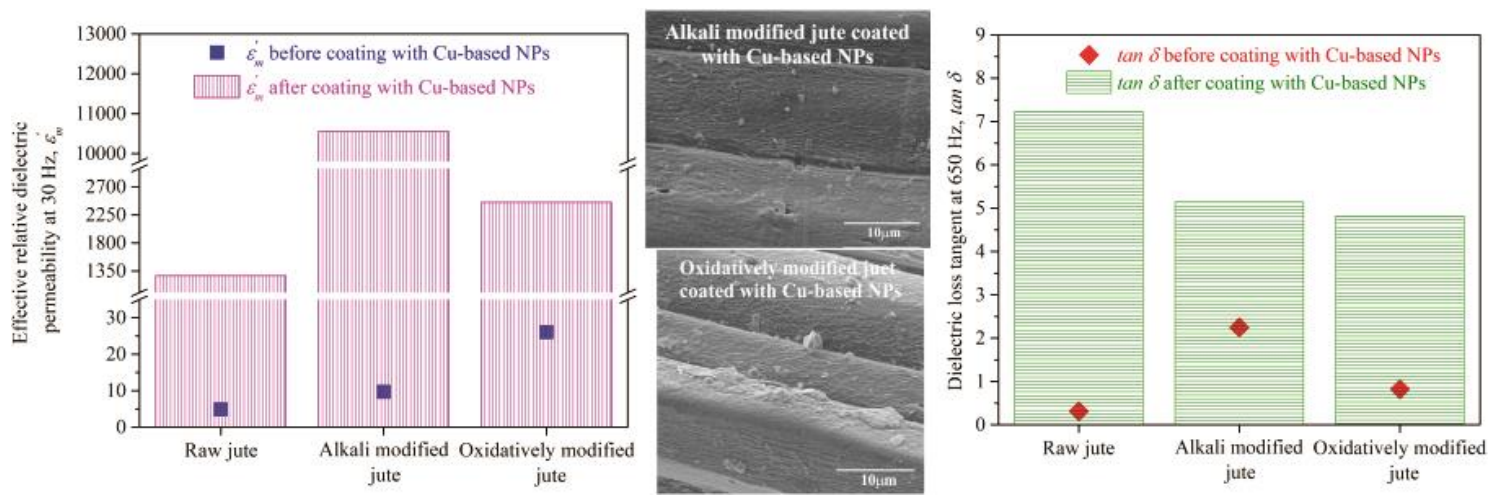

Graphical abstract

\section{Introduction}

60 From many years ago, due to the increased demand for cheap, biodegradable, renewable, and

61 recyclable fibers with good electrical and mechanical properties and superior insulation against

62 noise, jute dominate the world market for natural fibers behind cotton. The total production of jute

63 approximately adds up to those of all other plant natural fibers together (excluding cotton) and 
accounted for 3.37 million t in 2019 (FAO, 2019). Depending on their quality, jute fibers are mainly used for packaging (sackings, hessian cloth, etc.), and other diverse textiles (carpet backings, cords, home textiles) and non-textile applications including technical textiles (Samanta et al. 2020). Additionally, they are preferred for reinforcing both thermosetting and thermoplastic resins thanks to the stiffness and low micro-fibril angle (Ammayappan et al. 2020). Jute-based composites found a wide range of applications in numerous sectors such as construction, automotive, etc.

70 Nowadays, studies focus on obtaining jute fibers with unique properties and exceptional

71 functionalities are of great interest from the academic and industrial point of view. The most promising strategies for achieving above mentioned are fibers' modification and/or functionalization. Among many others, alkali (Ammayappan et al. 2020; Gupta 2020; Wanget al. 2019) and oxidative (Ibrahim et al. 2010; Khan et al. 2015) modifications still represent the most common routes for jute fibers' chemical modification. They provide selective hemicellulose or lignin removal, and therefore, obtaining cellulose-rich fibers with improved mechanical, thermal, electrokinetic, and sorption properties. The latter is closely related to fibers' electro-physical properties. Therefore, during the determination of fibers' electro-physical properties, especially in a condition of high humidity, their ability for moisture sorption should be considered since water has a much higher and more stable dielectric constant than fibers (Loss et al. 2020). Moreover, 81 previously published data (Ivanovska et al. 2019b, 2020) revealed that jute fibers' moisture sorption ability is directly conditioned by their fine structure, i.e. crystallinity indicating that this parameter plays an essential role in understanding the fabrics' electro-physical properties.

84 Furthermore, it has to be noted that some of the biggest benefits of the jute fibers' alkali and oxidative chemical modifications are increased availability of cellulose $\mathrm{OH}$ groups and the formation of new $\mathrm{COOH}$ groups, which is especially prominent in the case of oxidative modifications. Interactions between available $\mathrm{OH}$ groups (through ion-dipole interactions) and $\mathrm{COOH}$ groups (through ion interactions) with copper ions have been thoroughly studied over the years. In the last decade, copper ions and Cu-based nanoparticles (NPs) have been widely used for cellulose fibers' functionalization to develop fibers for various purposes, particularly for obtaining antimicrobial fibers (Emam et al. 2014; Marković et al. 2019, 2020; Loran et al. 2019) and impart self-cleaning (Montazer et al. 2015; Rezaie et al. 2017; Yang et al. 2017).

93 However, as per the authors' current knowledge, the parallel influence of complex phenomena (such 94 as fabrics' chemical composition, crystallinity, moisture sorption, $\mathrm{COOH}$ group content, structural 95 characteristics, and frequency of the electric field) on the electro-physical properties of chemically modified jute fabrics and jute fabrics decorated with $\mathrm{Cu}^{2+}$ ions or $\mathrm{Cu}$-based nanoparticles has not been yet reported. The determination of dielectric loss tangent and effective relative dielectric permeability in a condition of high humidity (i.e., $80 \% \mathrm{RH}$ ) is expected to attract a lot of attention due to fabric novel application possibilities and large potential for the replacement of expensive silver and gold-based NPs in the production of conductive materials.

\section{Experimental}

104 A raw jute fabric purchased from a commercial supplier was chemically modified with $17.5 \% \mathrm{NaOH}$ 105 (at room temperature, RT) or $0.7 \% \mathrm{NaClO}_{2}$ (at boiling temperature, BT) during different times 106 (detailed information regarding the modification procedure is given in the literature Ivanovska et al 107 (2019a)), as given in Fig. 1. 

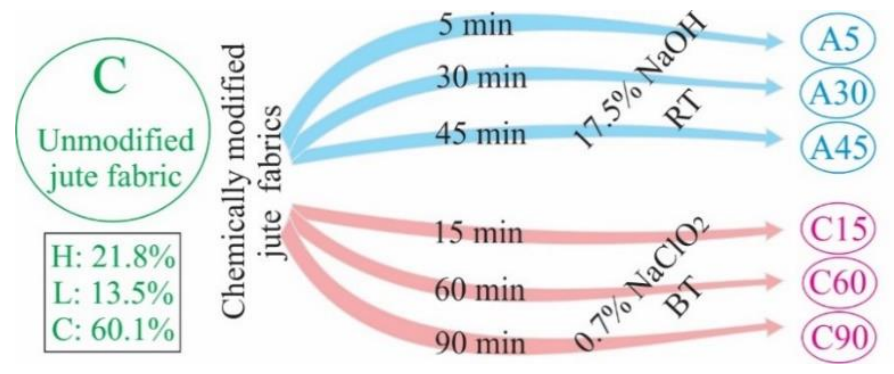

\begin{tabular}{l}
\hline H: $13.8 \%$, L: $12.9 \%$, C: $73.3 \%$ \\
\hline H: $12.3 \%$, L: $13.3 \%$, C: $74.3 \%$ \\
\hline H: $11.6 \%$, L: $12.5 \%$, C: $75.9 \%$ \\
\hline H: $21.8 \%$, L: $8.4 \%$, C: $69.8 \%$ \\
\hline H: $24.9 \%$, L: $5.0 \%$, C: $70.1 \%$ \\
\hline H: $25.3 \%$, L: $2.8 \%$, C: $71.9 \%$ \\
\hline
\end{tabular}

109 Fig. 1 Raw jute fabric chemical modification conditions, fabrics' abbreviations, and chemical compositions ( $\mathrm{H}$ - hemicelluloses, L - lignin, C - cellulose)

\subsection{Characterization of jute fabrics}

113 The jute fabrics' chemical composition was determined according to the procedure described in the literature (Ivanovska et al. 2019a).

115 The X-ray measurements were performed on a Rigaku Ultima IV diffractometer in a BraggBrentano configuration using $\mathrm{CuK} \alpha$ radiation. The diffraction data were acquired over the $2 \theta$ scattering angle (from $10^{\circ}$ to $60^{\circ}$ ) with a step of $0.05^{\circ}$ and an acquisition time of $0.5 \% \mathrm{~min}$. The obtained X-ray diffraction patterns were resolved into portions of cellulose $\mathrm{I}_{\beta}$, cellulose II lattice (French 2014), and amorphous region using Gaussian and Lorentzian distribution function. The conventional peak deconvolution involved curve fitting (by using a commercial software Peakfit v4.12) to the observed pattern with the individual visible peaks plus a very broad peak for the amorphous material (French 2020). The fabrics' crystallinity was calculated from the ratio of the area of all crystalline peaks to the total area.

The fabrics' moisture sorption was determined using Infrared Moisture Analyzer (Sartorius MA35). Before measurements, the fabrics were conditioned at $80 \%$ relative humidity to find the connection between the fabrics' moisture sorption and their electro-physical properties measured at the same relative humidity.

128 The jute fabric structural characteristics were characterized by the fabric thickness (measured on an AMES 414-10 thickness tester under a pressure of $10 \mathrm{kPa}$ ), fabric weight (determined using ISO 3801 (1977) standard), and fabric porosity (Ivanovska et al. 2020).

The $\mathrm{COOH}$ group content was determined by the calcium-acetate method described by Praskalo et al. (2009).

Field emission scanning electron microscopy (FESEM, Tescan MIRA $3 \mathrm{XMU}$ ) was used to investigate the surface morphology of studied jute fibers. Before the analysis, the fibers were sputtercoated with Au/Pd alloy using a Polaron SC502 Sputter Coater (Fison Instruments, United Kingdom).

\subsection{Jute fabrics' electro-physical properties}

The electro-physical properties of jute fabrics were measured on the Precise LCR Hameg 8118 

dielectric loss tangent $(\tan \delta)$ and effective relative dielectric permeability $\left(\varepsilon_{m}^{\prime}\right)$ were determined according to the Eqs. 1 and 2, respectively:

$$
\tan \delta=\frac{B \cdot l}{2 \cdot \pi \cdot f \cdot \varepsilon_{0} \cdot S}
$$

$$
\varepsilon_{m}^{\prime}=\frac{G}{B}
$$

149 where: $\varepsilon_{0}$ is vacuum permittivity $\left(8.854 \cdot 10^{-12} \mathrm{~F} / \mathrm{m}\right), S\left(\mathrm{~m}^{2}\right)$ is fabric surface, $f(\mathrm{~Hz})$ is frequency.

\subsection{Treatment with $\mathrm{CuSO}_{4}$ and in situ synthesis of $\mathrm{Cu}$-based NPs on} the jute fabrics

Selected jute fabrics (C, A30, and C90) were treated with $\mathrm{CuSO}_{4}$ according to the following procedure: $0.50 \mathrm{~g}$ of fabrics was immersed in $25 \mathrm{~mL}$ of $10 \mathrm{mM} \mathrm{CuSO}_{4}$ solution $(\mathrm{pH}=4.780)$ for 2 $\mathrm{h}$. Thereafter, the fabrics were rinsed three times with deionized water to eliminate the excessive copper ions and the obtained fabrics were denoted as $\mathrm{CCu}, \mathrm{A} 30 \mathrm{Cu}, \mathrm{C} 90 \mathrm{Cu}$.

The in situ synthesis of Cu-based NPs on jute fabrics was performed according to the method given by Marković et al. (2018a). First, the fabrics were treated with $\mathrm{CuSO}_{4}$, following the previously described procedure. After that, they were immediately dipped into the solution consisting of 0.050 $\mathrm{g}$ of sodium borohydride $\left(\mathrm{NaBH}_{4}\right)$ dissolved in $25 \mathrm{~mL}$ of $0.1 \mathrm{mM} \mathrm{NaOH}$ solution and the reduction process took place in the following $30 \mathrm{~min}$ at room temperature. The fabrics were thoroughly rinsed with deionized water and dried at room temperature. Jute fabrics coated with $\mathrm{Cu}$-based NPs were marked as CCuNPs, A30CuNPs, and C90CuNPs.

\subsection{Determination of $\mathrm{Cu}^{2+}$ uptake and total content of $\mathrm{Cu}$ after}

\section{reduction}

The $\mathrm{Cu}^{2+}$ uptake on the $\mathrm{CCu}, \mathrm{A} 30 \mathrm{Cu}$, and $\mathrm{C} 90 \mathrm{Cu}$ was calculated based on the concentration of residual copper in the solution, which was measured using inductively coupled plasma optical emission spectrometry (ICP-OES, iCAP 6500 Duo ICP, Thermo Fisher Scientific, Cambridge, United Kingdom). The measurements were performed at the $\mathrm{Cu}$ I $324.754 \mathrm{~nm}$ emission-line. Quality control was carried out using blank samples, matrix-matched calibration solutions, and triplicate analyses of each sample. The $\mathrm{Cu}^{2+}$ uptake was calculated as follows Eq. 3:

where: $c_{0}$ and $c_{t}$ are the copper concentrations in the initial solution and the solution after $2 \mathrm{~h}$ of adsorption ( $\mu \mathrm{mol} / \mathrm{l}) ; V$ is solution volume (l) and $m$ is the weight of a dry jute fabric (g).

ICP-OS was also used for determining the total content of $\mathrm{Cu}$ in the jute fabrics after the reduction process. In brief, $0.25 \mathrm{~g}$ of fabric was mixed in a vessel with a mixture of $10 \mathrm{ml}$ of $65 \%$ $\mathrm{HNO}_{3}$ solution and $1 \mathrm{ml}$ of $30 \% \mathrm{H}_{2} \mathrm{O}_{2}$ and then heated with microwave energy (Advanced Microwave Digestion System ETHOS 1, Milestone, Italy) for $30 \mathrm{~min}$. The temperature was raised to $200{ }^{\circ} \mathrm{C}$ in the first $15 \mathrm{~min}$, maintained at this degree in the next $20 \mathrm{~min}$, and then cooled down 


\section{Results and discussion}

\subsection{Characterization of chemically modified jute fabrics}

186

187

188
Well-known alkali and oxidative modifications (Fig. 1) were utilized as essential tools for studying the relationship between the jute fibers' structure and their electro-physical properties. By extending the alkali or oxidative modification duration, the jute fabrics with decreased hemicellulose or lignin content as well as increased cellulose content were obtained, Fig. 1.

More precisely, after 5, 30, and 45 min of alkali modifications, the hemicellulose content within fabrics A5, A30, and A45 decreased by approximately 37\%, 44\%, and 47\%, while the cellulose content increased by about $22 \%, 24 \%$, and $26 \%$ compared to that of unmodified fabric $(\mathrm{C})$. The changes in the fibers' molecular structure are accompanied by changes in their fine structure. For example, with extending the mercerization duration from 5 to $30 \mathrm{~min}$, the swelling and shrinkage of the ultimate cells increased resulting in cellulose fibrils' disorientation (i.e., decreased crystallinity for $11.5 \%$, Table 1) and increased polymorphic conversion from cellulose $\mathrm{I}_{\beta}$ to cellulose II, and consequently increased cellulose II / cellulose I ratio (from 0.84 to 1.37). Furthermore, in the case of the longest modification time (45 min), the cellulose II / cellulose I ratio within the fabric A45 significantly increased; the entire fibers are converted into a swollen state and newly exposed cellulose hydroxyl groups can interact with each other to form a different type of hydrogen bonds (Yue et al. 2015) contributing to cellulose chains' rearrangement in an ordered structure, i.e., increased crystallinity, Table 1 . The parallel influence of both fine and molecular fiber structure can be used to explain the enhanced ability of the alkali modified fibers' for moisture sorption, Table 1. Namely, it occurs as a consequence of hemicellulose removal from interfibrillar regions, followed by decreased crystallinity, pronounced elementary fibers' liberalization, and increased effective surface area allowing higher availability of cellulose hydroxyl groups as well as storing of water molecules inside fibers' free volume (Ivanovska et al. 2019b).

Table 1 Jute fabrics' characterization

\begin{tabular}{|c|c|c|c|}
\hline Sample abbreviation & Crystallinity, \% & $\begin{array}{c}\text { Cellulose II/ Cellulose } \\
\text { I ratio }\end{array}$ & $\begin{array}{c}\text { Moisture sorption at } \\
80 \% \text { RH, \% }\end{array}$ \\
\hline C & 72.8 & $/$ & 14.8 \\
\hline A5 & 59.1 & 0.84 & 16.56 \\
\hline A30 & 52.3 & 1.37 & 16.38 \\
\hline A45 & 67.3 & 2.22 & 15.86 \\
\hline C15 & 78.0 & $/$ & 15.54 \\
\hline C60 & 81.3 & $/$ & 15.48 \\
\hline C90 & 84.9 & $/$ & 15.05 \\
\hline
\end{tabular}

Depending on oxidative modifications' duration, the jute fabrics with gradually decreased lignin content and increased cellulose content were obtained; fabrics C15, C60, and C90 have about 38\%, $63 \%$, and $79 \%$ lower lignin content and about 16\%, 17\%, and 19\% higher cellulose content compared to the unmodified fabric, Fig. 1. Having in mind that the lignin is a relative hydrophobic heteropolymer composed of phenyl propane units connected through carbon-carbon bonds or ether bonds (Yang et al. 2018), the increased moisture sorption of oxidatively modified jute fabrics (i.e., fabrics with decreased lignin content) was expected. However, a clear correlation between the degree of delignification and fabrics' moisture sorption was not established since fabrics C15 and C60 have different lignin content (Fig. 1) but very similar moisture sorption values, Table 1. On the other hand, progressive lignin removal (fabric C90) from middle lamellae contributed to its 
220 homogenization and makes the penetration of water molecules within fibers difficult resulting in 221 lower moisture sorption ability compared to fabrics C15 and C60, Table 1. In parallel, the cellulose 222 hydroxyl groups present at the crystallite surfaces become more exposed and ready to form hydrogen 223 bonds with surrounding amorphous regions. Agarwal et al. (2017) reported that these hydrogen 224 bonds caused a higher number of cellulosic molecules in the amorphous regions to move closer to 225 the crystalline regions and become aligned causing increased crystallinity. This statement is in 226 agreement with the results presented in Table 1; fabrics C15, C60 and C90 have 7.1\%, 11.7\%, and $22716.6 \%$ higher crystallinity compared to the unmodified fabric, respectively.

\subsection{Jute fabrics' electro-physical properties in a condition of high}

\section{0 humidity}

231 The effect of five variables, four internal (jute fabrics' chemical composition and structural characteristics, fibers' fine structure and moisture sorption) and one external (frequency of electric field) on the fabrics' electro-physical properties in a condition of high humidity was studied. The dielectric loss tangent (i.e., material dissipation factor) corresponds to the energy losses occurring due to the motion or rotation of atoms or molecules within the fabric positioned in a periodic electric

236 field (Asanovic et al. 2020). The fabric effective relative dielectric permeability (i.e., a real part of 237 the permittivity) is a measure of how much energy from an external electric field is stored in it and 238 describes its ability to polarize (Fares et al. 2019; Loss et al. 2020).

\subsubsection{Dielectric loss tangent}

241 The dielectric loss tangent $\tan \delta$ ) of jute fabrics having different molecular and fine structures, moisture sorption, and fabric structural parameters (Fig. 1 and Table 1) was measured in the frequency range from $30 \mathrm{~Hz}$ to $140 \mathrm{kHz}$ at $80 \% \mathrm{RH}$, Fig. 2. The obtained results revealed that the tan $\delta$ values of unmodified fabric (C) and fabrics with the lowest hemicellulose and lignin content (A45, and C90) gradually decrease with increasing frequency. According to Norimoto and Yamada (1970), higher tan $\delta$ values in the frequency range between $30 \mathrm{~Hz}$ and $100 \mathrm{~Hz}$ can be ascribed by the orientation polarization, i.e., by the movement of cellulose, hemicellulose, and lignin molecules. Taking into consideration above mentioned together with the performed chemical modifications, it is clear that due to the progressive hemicellulose or lignin removal (A45, and C90), the free spaces within/between the fibrils become larger enabling easy movement of structural components' molecules, and thus resulting in higher energy losses, i.e., higher energy dissipation within the fabrics A45 and C90 than within unmodified fabric (C), Fig. 2. However, at frequencies above 100 $\mathrm{Hz}$, the molecular vibrations become intensive, the orientation polarization of the jute components' molecules does not take place completely, and hence, the $\tan \delta$ values decrease with increasing the

255 frequency ( $\mathrm{Li}$ et al. 2014). The obtained results are in line with the previously published data

256 (Asanovic et al. 2020; Fares et al. 2019; Rajini et al. 2013). 

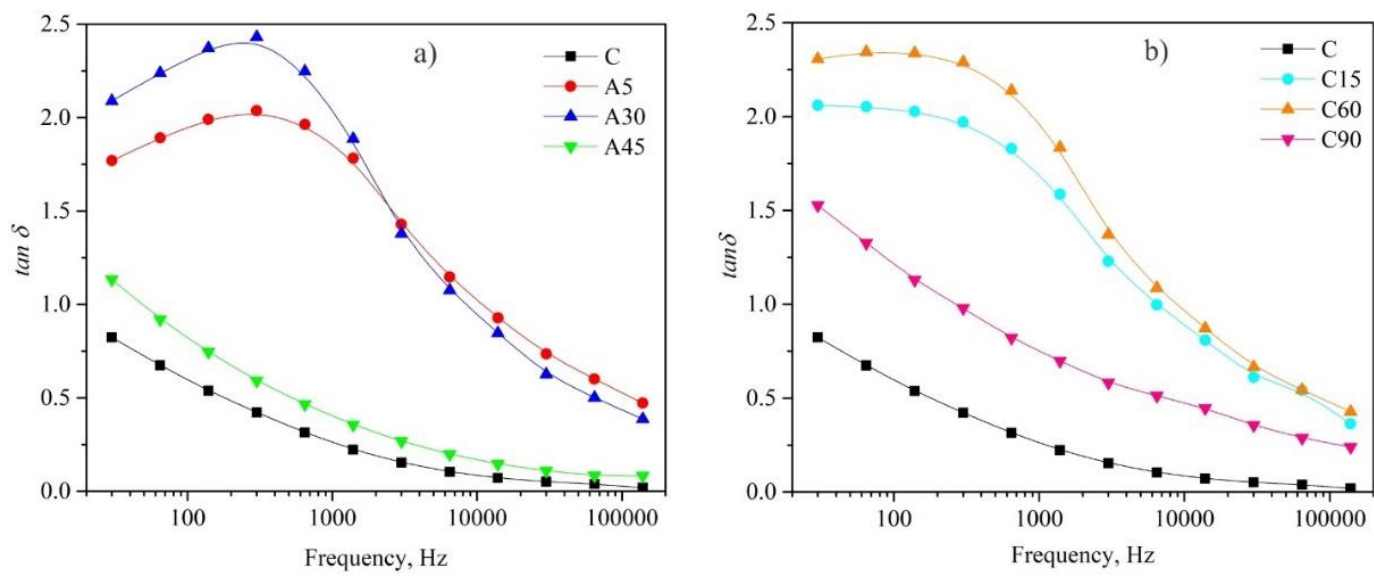

258 Fig. 2 Dielectric loss tangent (tan $\delta$ ) of unmodified and: a) alkali and b) oxidatively modified jute fabrics

260 The frequency dependencies of $\tan \delta$ of other chemically modified jute fabrics (A5, A30, C15, and C60) are not the same as those of fabrics C, A45, and C90. From Figure 2, it is evident that the tan $\delta$ values of A5 and A30 increase with increasing the frequency and reach a maximum at $300 \mathrm{~Hz}$. In the case of the oxidatively modified fabrics $\mathrm{C} 15$ and $\mathrm{C} 60$, maximal $\tan \delta$ values were observed at $30 \mathrm{~Hz}$ and $65 \mathrm{~Hz}$, respectively. The $\beta_{w e t}$ relaxations noticed in the frequency range between $30 \mathrm{~Hz}$ and $300 \mathrm{~Hz}$ (for A5, A30, C15, and C60) can be associated with the orientation motion of the polar groups present in fibers (primarily hydroxyl and carboxyl groups), water, and structures formed by introducing water (Asanovic et al. 2020; Saukkonen et al. 2015). This type of relaxation was also observed for damp cotton (at 68-95\% RH, Morton and Hearle (2008)), paper having different hemicellulose content (at 65\% RH, Saukkonen et al. (2015)), and viscose/polypropylene fabrics (at $80 \%$ RH, Asanovic et al. (2020)). Similarly, Einfeldt et al. (2001) reported that the dielectric relaxation in cellulose-containing materials strongly depends on the interaction between cellulose and aqueous complexes formed at the polymer-water interface, so it is reasonable to assume that the hemicellulose or lignin removal (i.e., increased availability of cellulose hydroxyl groups) changes the interaction between water molecules and cellulose. High coefficients of linear correlation between the fabric moisture sorption and $\tan \delta$ values (at $30 \mathrm{~Hz})$ for alkali $(\mathrm{r}=0.889)$ and oxidatively $(r=0.962)$ modified jute fabrics additionally prove that statement. However, the jute fabrics' molecular structure and moisture sorption are not sufficient to explain their $\tan \delta$ values; the influence of fabrics' crystallinity should be studied since according to Rajini et al. (2013), increased crystallinity results in a decreased $\tan \delta$ values. This was proven only in the case of alkali modified jute fabrics, whereby a very high coefficient of negative linear correlation $(r=-0.996)$ between their crystallinity and $\tan \delta$ values (at $30 \mathrm{~Hz}$ ) was observed. In other words, the lower crystallinity and increased number of available cellulose hydroxyl groups that can sorb/retain moisture due to their interactions with water molecules (from the air) contributed to higher $\tan \delta$ values of alkali modified jute fabrics compared to the unmodified fabric. Lastly, since the fabrics' structural characteristics changed due to the applied chemical modifications (Table 2), their impact on $\tan \delta$ should be also considered. In the case of alkali modified jute fabrics, with increasing the fabric thickness and

289 Table 2 Jute fabrics' structural parameters $(*$ The results for fabric thickness and weight were

290 previously published in Ivanovska et al. 2020)

\begin{tabular}{|c|c|c|c|}
\hline Sample abbreviation & Fabric thickness, $\mathrm{mm}$ & Fabric weight, $\mathrm{g} / \mathrm{m} 2$ & Porosity, $\%$ \\
\hline C* & 0.762 & 266 & 61.0 \\
\hline A5* & 1.773 & 495 & 29.4 \\
\hline A30* & 1.868 & 529 & 25.6 \\
\hline A45 & 1.751 & 523 & 33.6 \\
\hline
\end{tabular}




\begin{tabular}{|c|c|c|c|}
\hline C15* & 1.118 & 317 & 55.2 \\
\hline C60* & 1.221 & 270 & 57.8 \\
\hline C90* & 1.133 & 262 & 60.4 \\
\hline
\end{tabular}

\subsubsection{Effective relative dielectric permeability}

The frequency dependence of effective relative dielectric permeability $\left(\varepsilon_{m}^{\prime}\right)$ of unmodified and chemically modified jute fabrics is given in Fig. 3. For all fabrics, the highest $\varepsilon_{m}^{\prime}$ was observed at the lowest frequency $(30 \mathrm{~Hz}$ ) which can be explained by the fact that when the fabrics are subjected to an external electric field, their dipoles interact with it and tend to align in the same direction as in the case when they are not subjected to electric filed (i.e., randomly alignment) resulting in higher $\varepsilon_{m}^{\prime}$ (Fares et al. 2019). However, as the frequency increases (from $30 \mathrm{~Hz}$ up to $140 \mathrm{kHz}$ ), the dipoles' direction randomness also increases, the molecules lagged behind the alteration of the applied electric field contributing to lower $\varepsilon_{m}^{\prime}$, Fig. 3.
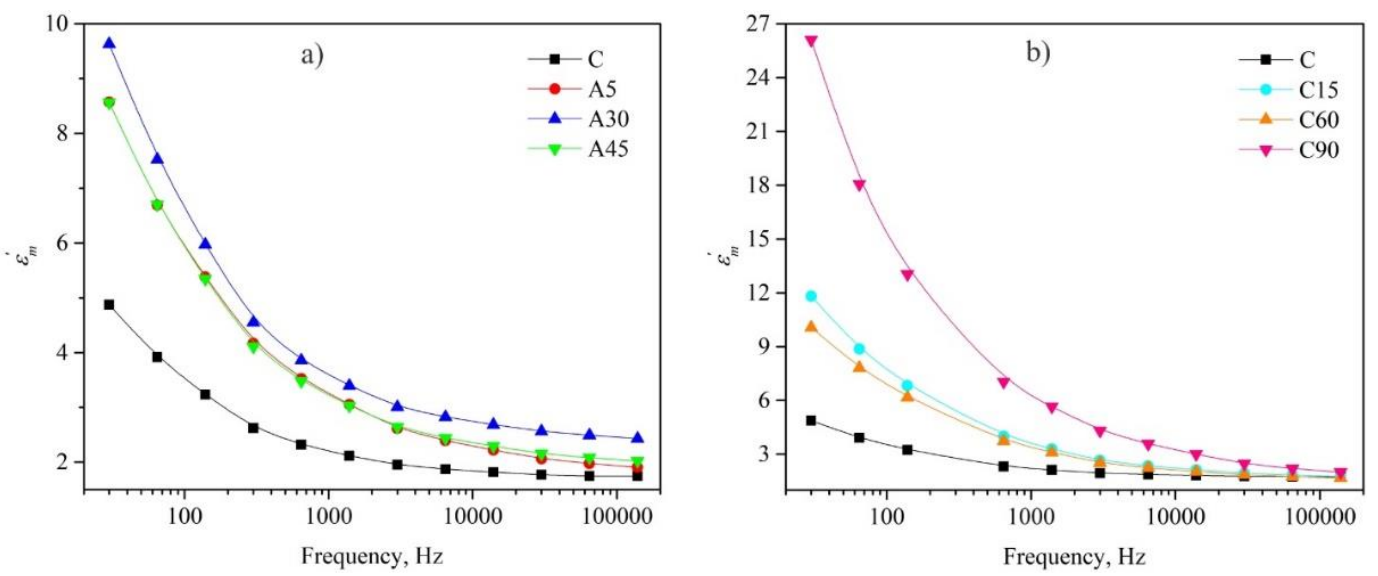

Fig. 3 Effective relative dielectric permeability $\left(\varepsilon_{m}^{\prime}\right)$ of unmodified and: a) alkali and b) oxidatively modified jute fabrics

Observing in parallel the tan $\delta$ (Fig. 2) and $\varepsilon_{m}^{\prime}$ (Fig. 3) of unmodified fabric, it can be concluded that the interaction of dipole structures with the participation of hemicelluloses and lignin is strong supporting the assumption that the untreated fabric's lowest $\varepsilon_{m}^{\prime}$ is at least partly caused by the strengthening of the dipole interaction. Additionally, the untreated fabric's lowest $\varepsilon_{m}^{\prime}$ can be attributed to its lowest content of cellulose $(60.1 \%$, Table 1) and carboxyl groups $(207 \mu \mathrm{mol} / \mathrm{g}$, Fig. 4) as well as the highest content of surface impurities (Fig. 5) responsible for lower accessibility of functional groups. After the chemical modifications, these surface impurities were to some extend removed, which together with the hemicellulose or lignin removal and increased cellulose content lead to better accessibility of functional groups (including newly exposed cellulose hydroxyl groups and newly formed carboxyl groups, Fig. 4). In the presence of moisture (80\% RH), cellulose hydroxyl groups, as well as newly formed carboxyl groups, contributed to an increased anionic charge of modified fabrics thus increased their $\varepsilon_{m}^{\prime}$, Fig. 3. Besides all the above mentioned, it is known that the $\varepsilon_{m}^{\prime}$ as $\tan \delta$ is also sensitive to fabric's moisture content.

As it was listed in Tables 1 and 2, the alkali modified jute fabrics are characterized by a higher amount of amorphous regions as well as lower porosity (i.e., lower spaces between the yarns within the fabric) indicating that the absorbed water is most probably located as bound water. Namely, the water molecules penetrate inside the fiber, break the secondary interactions between the cellulose macromolecules, and after that, they are absorbed into the fibers by hydrogen bonds causing fibers' swelling. All mentioned will contribute to the creation of favorable conditions for better mobility of 
the fibers' cellulose chains, dipoles' displacement, and rotation enhancing the electric polarization process (Cerovic et al. 2013), i.e., increasing $\varepsilon_{m}^{\prime}$. This behavior is prominent for fabric A30 having the highest moisture sorption value which is closely related to its chemical composition and amorphous regions' expansion (i.e., decreased crystallinity). Because fabrics' electro-physical properties refer to a "fiber-moisture-air" system, besides moisture sorption and crystallinity, the fabrics' structural characteristics also affect their $\varepsilon_{m}^{\prime}$. For example, a slightly higher $\varepsilon_{m}^{\prime}$ value was noticed for the fabric A30 having slightly lower porosity as well as higher fabric thickness compared to the other alkali modified jute fabrics. -0.854 and 0.985 are the linear correlations between alkali modified fabrics' $\varepsilon_{m}^{\prime}$ values (at $30 \mathrm{~Hz}$ ), porosity, and thickness, respectively.

A comparative analysis of differently modified jute fabrics (Fig. 3) showed that the oxidatively modified fabrics' $\varepsilon_{m}^{\prime}$ values are higher than that of alkali modified ones, which is especially pronounced for fabric C90. About 2.7 times higher $\varepsilon_{m}^{\prime}$ (at $30 \mathrm{~Hz}$ ) observed for the fabric C90 compared to that of A30 can be attributed to different factors acting in parallel. Namely, in the case of high air humidity $(80 \% \mathrm{RH})$, part of the absorbed water in the fabric is located as bound water and the other part as bulk-free water. According to Saukkonen et al. (2015), adsorbed water molecules are neither free to move around nor free to change their orientation, and consequently their $\varepsilon_{m}^{\prime}$ are much lower than that of free water $\left(\varepsilon_{m}^{\prime}=81\right)$. For oxidatively modified jute fabrics having higher crystallinity and fabric porosity (Tables 1 and 2) compared to the alkali modified, it can be assumed that absorbed water is located as bulk-free water, and, therefore, it has a strong influence on fabrics' $\varepsilon_{m}^{\prime}$. In other words, the oxidatively modified fabrics' $\varepsilon_{m}^{\prime}$ increased as a consequence of the higher number of water's polar groups present at the fabric surface as well as between the yarns within the fabric. On the other hand, oxidatively modified jute fabrics have considerably higher contents of carboxyl groups as compared to alkali modified, which is one more factor affecting their higher $\varepsilon_{m}^{\prime}$. In the investigation conducted by Simula (1999), the increased content of carboxyl groups is responsible for higher $\varepsilon_{m}^{\prime}$ of the birch than that of pine kraft pulp. According to all the above discussed, it can be postulated that compared to alkali modifications (i.e., hemicellulose removal), oxidative modifications (i.e., lignin removal) encourage the freedom of water molecules to take part in polarization processes.

\subsection{Characterization of jute fabrics decorated with $\mathrm{Cu}^{2+}$ ions or $\mathrm{Cu}$ -} 353 based NPs

354 Bearing in mind the fact that the carboxyl groups affect the fabrics' $\varepsilon_{m}^{\prime}$ and at the same time represent 355 potential sites for binding metal ions through ion-exchange, unmodified (C) and chemically 356 modified jute fabrics having the highest $\varepsilon_{m}^{\prime}\left(\mathrm{A} 30\right.$ and $\mathrm{C} 90$ ) were treated with $\mathrm{CuSO}_{4}$ solution (fabrics 357 marked as $\mathrm{CCu}, \mathrm{A} 30 \mathrm{Cu}$, and $\mathrm{C} 90 \mathrm{Cu}$ ) to further improve their $\varepsilon_{m}^{\prime}$. The $\mathrm{Cu}^{2+}$ uptake was calculated 358 and presented in Fig. 4. During the exploitation under specific conditions, the reduction of copper 359 may occur. To evaluate the changes in fabrics' $\varepsilon_{m}^{\prime}$ induced by the reduction of copper ions, after the 360 treatment with $\mathrm{CuSO}_{4}$, the jute fabrics were immediately dipped into a solution of $\mathrm{NaBH}_{4}$ (fabrics 361 denoted as CCuNPs, A30CuNPs, and C90CuNPs), and the total content of $\mathrm{Cu}$ after reduction was 362 determined (Fig. 4). 


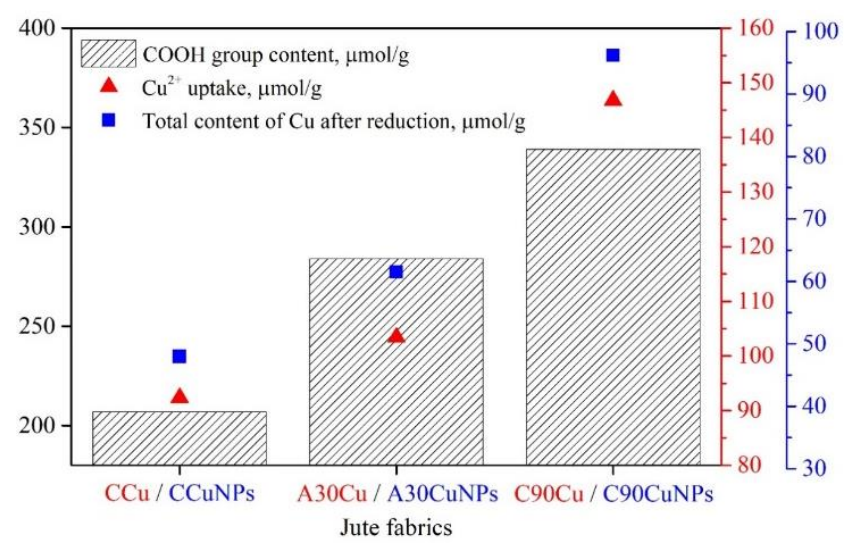

364 Fig. 4 Relationship between $\mathrm{COOH}$ group content, $\mathrm{Cu}^{2+}$ uptake, and total content of $\mathrm{Cu}$ after

365 reduction in the selected jute fabrics

366 From Fig. 4, it is clear that a higher content of $\mathrm{COOH}$ groups present in the jute fabrics provided higher $\mathrm{Cu}^{2+}$ uptake and thus higher total content of $\mathrm{Cu}$ after the reduction. This behavior was also observed for cotton fabrics coated with Cu-based NPs (Marković et al. 2018a, 2018b). In the current investigation, 0.910 and 0.941 are the linear correlations between $\mathrm{Cu}^{2+}$ uptake, the total content of $\mathrm{Cu}$ after reduction, and the $\mathrm{COOH}$ group content. It has to be noted that the total $\mathrm{Cu}$ contents were about $34-48 \%$ lower than that determined after adsorption due to the releasing of unbounded or weakly bonded copper ions during the reduction.

Furthermore, the jute fibers' surface morphology before and after the copper reduction was assessed by FESEM, Fig. 5. SEM images of untreated fiber (C) reveal a relatively uneven and rough surface covered with waxes and pectin. Besides the fact that the total content of $\mathrm{Cu}$ after the reduction account for about $48 \mu \mathrm{mol} / \mathrm{g}$, the presence of single or agglomerated Cu-based NPs is not visible on CCuNPs surface since NPs are probably formed next to and/or covered fibers' surface impurities. The situation is somewhat different in the case of chemically modified jute fibers coated with $\mathrm{Cu}$ based NPs (A30CuNPs and C90CuNPs). Their SEM images are in accordance with the results given in Fig. 4, i.e., the larger the uptake of $\mathrm{Cu}^{2+}$ on the fibers, the larger the amounts of $\mathrm{Cu}$-based NPs on their surfaces. A few single Cu-based NPs were observed across the A30CuNPs surface, while single irregularly shaped and agglomerated Cu-based NPs (along with a low amount of fiber impurities) were distributed over the C90CuNPs surface.
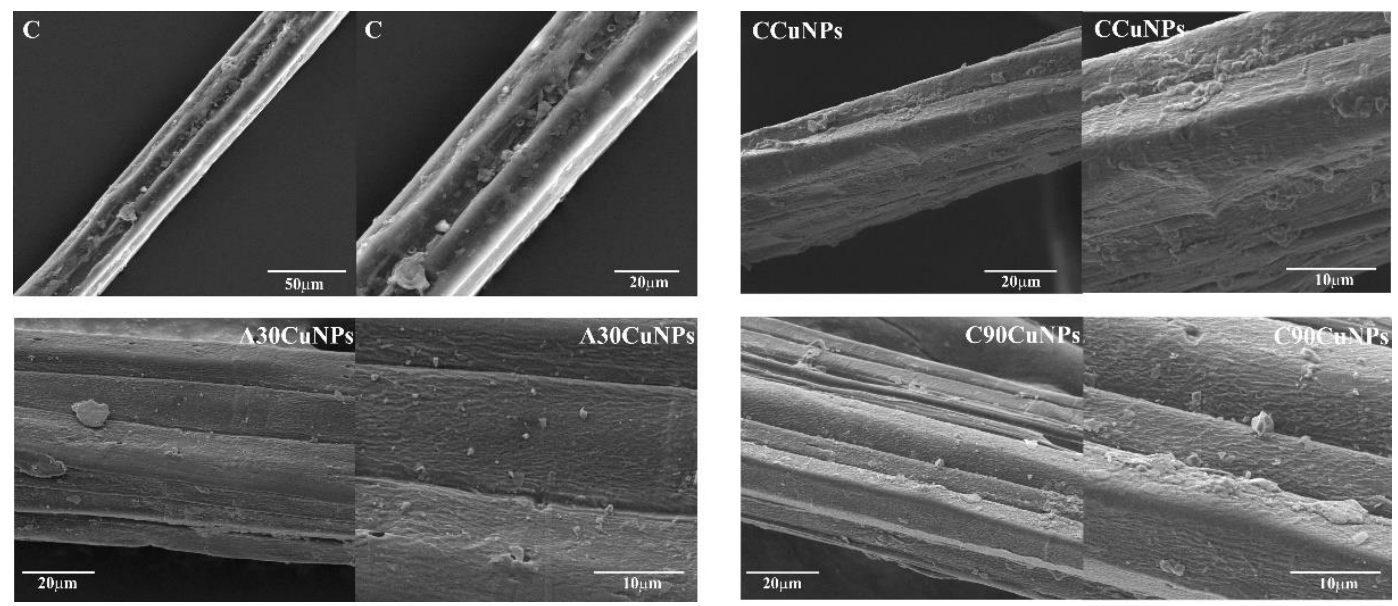

385 Fig. 5 SEM photographs of untreated jute fibers (C), and fibers coated with Cu-based NPs

386 (CCuNPs, A30CuNPs, C90CuNPs)

387 The X-ray diffraction analysis is another technique utilized to verify the Cu-based NPs' structure, 388 as well as the presence of different cellulose polymorphs, Fig. 6 . The shoulder at $2 \theta$ of $35.5^{\circ}$ 
observed in the CCuNPs, A30CuNPs, and C90CuNPs diffractograms implied the formation of (111) crystal planes of base centered monoclinic crystal phase of CuO (ICDD 01-089-5899) (Marković et al. 2019). A broad low-intensity peak at $2 \theta$ of $45.8^{\circ}$ corresponded to the (111) crystalline planes of the metallic $\mathrm{Cu}$ (JCPDS 99-0034) (Dube et al. 2020). In the A30CuNPs diffractogram, two more shoulders are visible: one at $2 \theta$ of $28.8^{\circ}$ assigning to the shifted peak characteristic for (110) crystal plane of cubic $\mathrm{Cu}_{2} \mathrm{O}$ (ICDD 01-077-0199), and the other at $2 \theta$ of $42.5^{\circ}$ corresponding to $\mathrm{CuO}$ (200) crystal plane (PDF 278-0428) (Marković et al. 2020). To summarize, NPs present on CCuNPs and C90CuNPs surfaces consist of metallic $\mathrm{Cu}$ and $\mathrm{CuO}$, while the $\mathrm{Cu}$-based NPs synthesized on the A30CuNPs surface can be considered as a mixture of metallic $\mathrm{Cu}$ and both oxides $\mathrm{CuO}$ and $\mathrm{Cu}_{2} \mathrm{O}$. A mixture of copper oxides was also detected on the cotton fabric modified with polycarboxylic acids and Cu-based NPs (Marković et al. 2018b), while the Cubased NPs synthesized on the TEMPO modified cotton fabric contained a mixture of metallic $\mathrm{Cu}$ and $\mathrm{Cu}_{2} \mathrm{O}$ (Dhineshbabu and Rajendran 2016; Marković et al. 2018a).
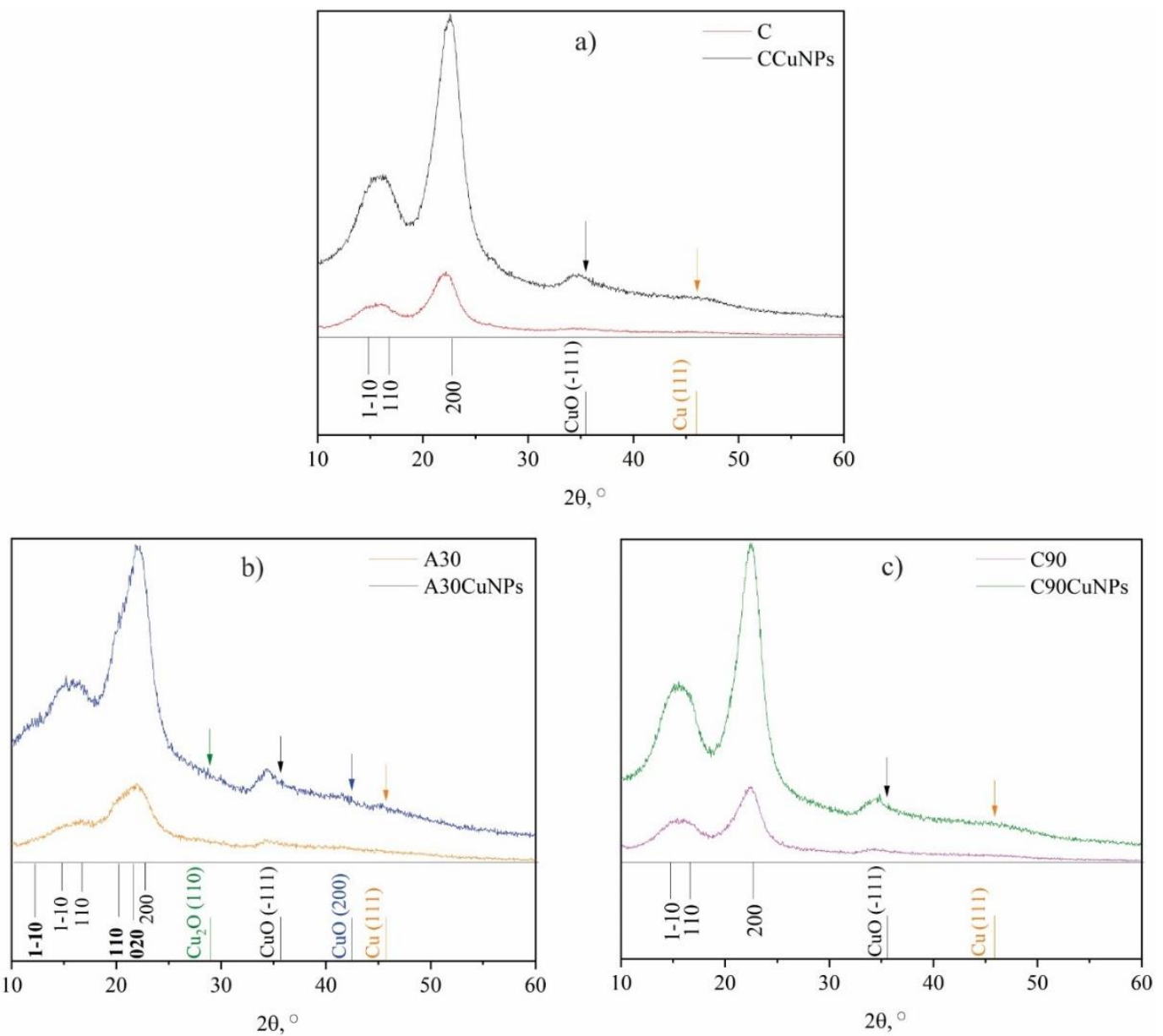

Fig. 6 X-ray diffraction patterns of jute fabrics before and after in situ synthesis of Cu-based NPs

It has to be emphasized that the X-ray diffraction patterns of the fabrics before and after in situ synthesis of Cu-based NPs show peaks that are characteristic for cellulose $\mathrm{I}_{\beta}$ (corresponding to the reflections (1-10), (110) and (200), French (2014)), Fig. 6b. On the other hand, both cellulose polymorphs ( $\mathrm{I}_{\beta}$ and II) coexist in the X-ray diffraction pattern of A30 and A30CuNPs due to the incomplete conversion (57.7\%, Ivanovska et al. (2020)) from cellulose $\mathrm{I}_{\beta}$ to cellulose II (the reflections for cellulose II (1-10), (110), and (020) are shifted according to French (2014), Fig. 6b, 


\subsection{Electro-physical properties of decorated with $\mathrm{Cu}^{2+}$ ions or $\mathrm{Cu}-$}

\section{3 based nanoparticles}

414 Jute fabrics containing $\mathrm{Cu}^{2+}$ ions and coated with $\mathrm{Cu}$-based NPs were subjected to dielectric 415 measurements. By comparing the results presented in Figs. 3 and 7a, it is evident that $\mathrm{CCu}, \mathrm{A} 30 \mathrm{Cu}$, 416 and $\mathrm{C} 90 \mathrm{Cu} \varepsilon_{m}^{\prime}$ values (at $30 \mathrm{~Hz}$ ) are about 4.9, 6.7, and 4.6 times higher compared to $\mathrm{C}$, $\mathrm{A} 30$, and $417 \mathrm{C} 90 \varepsilon_{m}^{\prime}$ values, respectively. Additionally, the $\mathrm{CuSO}_{4}$ treated fabrics' $\varepsilon_{m}^{\prime}$ increases as the $\mathrm{Cu}^{2+}$ 418 uptake increases: $\mathrm{CCu}<\mathrm{A} 30 \mathrm{Cu}<\mathrm{C} 90 \mathrm{Cu}$, Figs. 4 and $7 \mathrm{a}$. On the other hand, the relation between 419 the total content of $\mathrm{Cu}$ after reduction (Fig. 4) and the fabrics' CuNPs, A30CuNPs, and C90CuNPs $420 \quad \varepsilon_{m}^{\prime}$ (Fig. 7b) was not established pointing out that some other factor/s influence/s the $\varepsilon_{m}^{\prime}$ of fabrics coated with $\mathrm{Cu}$-based NPs. Observing in parallel the SEM photographs (Fig. 5) and the results presented in Fig. 7b, it seems that the NPs' agglomeration is the major reason for C90CuNPs lower $\varepsilon_{m}^{\prime}$ compared to fabric A30CuNPs, which highest $\varepsilon_{m}^{\prime}$ is attributed to the presence of an evenly distributed single $\mathrm{Cu}$-based NPs. Surprisingly, the jute fabrics coated with $\mathrm{Cu}$-based NPs have about 21-163 times higher $\varepsilon_{m}^{\prime}$ (at $30 \mathrm{~Hz}$ ) than those treated with $\mathrm{CuSO}_{4}$, Fig. 7. This behavior is very valuable since, during the exploitation in specific conditions contributing to copper reduction, the jute fabrics will be able to store much more energy from an electric field than before the exploitation, which further extends their lifetime.
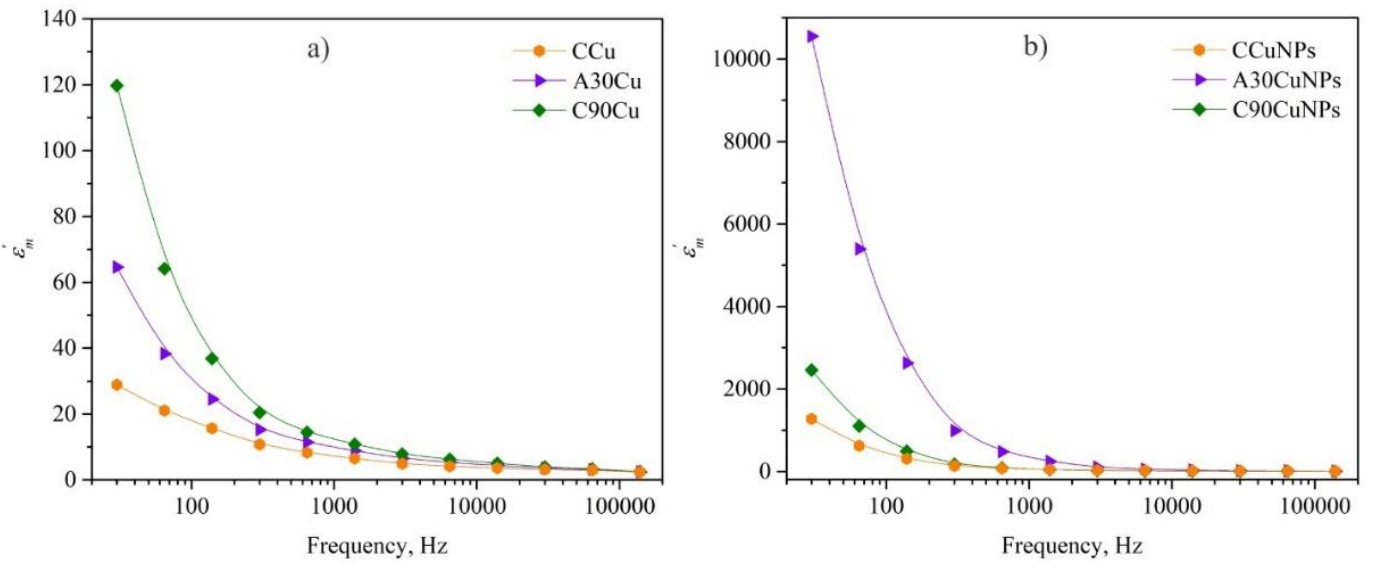

430 Fig. 7 Effective relative dielectric permeability $\left(\varepsilon_{m}^{\prime}\right)$ of jute fabrics: a) treated with $\mathrm{CuSO}_{4}$ and b) coated with $\mathrm{Cu}$-based NPs

The increase in the $\mathrm{CuSO}_{4}$ treated fabrics' $\tan \delta$ values is in line with the increase in their $\varepsilon_{m}^{\prime}$ values. Namely, jute fabrics treated with $\mathrm{CuSO}_{4}(\mathrm{CCu}, \mathrm{A} 30 \mathrm{Cu}$, and $\mathrm{C} 90 \mathrm{Cu})$ have up to 5.7 times enhanced energy dissipation (at $30 \mathrm{~Hz}$ ) than before the treatment, Figs. 2a and 8a. However, after the coating with Cu-based NPs, the fabrics' $\tan \delta$ values did not significantly change, while their frequency dependence is completely different from that after the treatment with $\mathrm{CuSO}_{4}$, Fig. 8. CCuNPs, A30CCuNPs, and C90CuNPs tan $\delta$ values increase with increasing the frequency and reach a maximum at 650,140 , and $6500 \mathrm{~Hz}$, respectively, and, thereafter, the $\tan \delta$ values decrease. Taking into consideration the total content of Cu after the reduction (Fig. 4) and NPs distribution on fibers' surfaces (Fig. 5), it can be concluded that with increasing the total content of $\mathrm{Cu}$ after the reduction and formation of single and agglomerated NPs, the movement of structural components' molecules (between 300 and $3000 \mathrm{~Hz}$ ) becomes difficult and thus resulting in lower energy dissipation within the fabrics A30CuNPs and C90CuNPs than within fabric CCuNPs. Interestingly, fabric C90CuNPs has almost the same tan $\delta$ values at the lowest and the highest frequencies $(30 \mathrm{~Hz}$ and $140 \mathrm{kHz}$, respectively) indicating that the highest total content of $\mathrm{Cu}$ after reduction along with the presence of agglomerated Cu-based NPs did not allow to intensify the molecular vibrations and the electric from the results obtained for $\mathrm{C} 90$ and $\mathrm{C} 90 \mathrm{Cu}$, Figs. $2 \mathrm{a}$ and $8 \mathrm{a}$. 

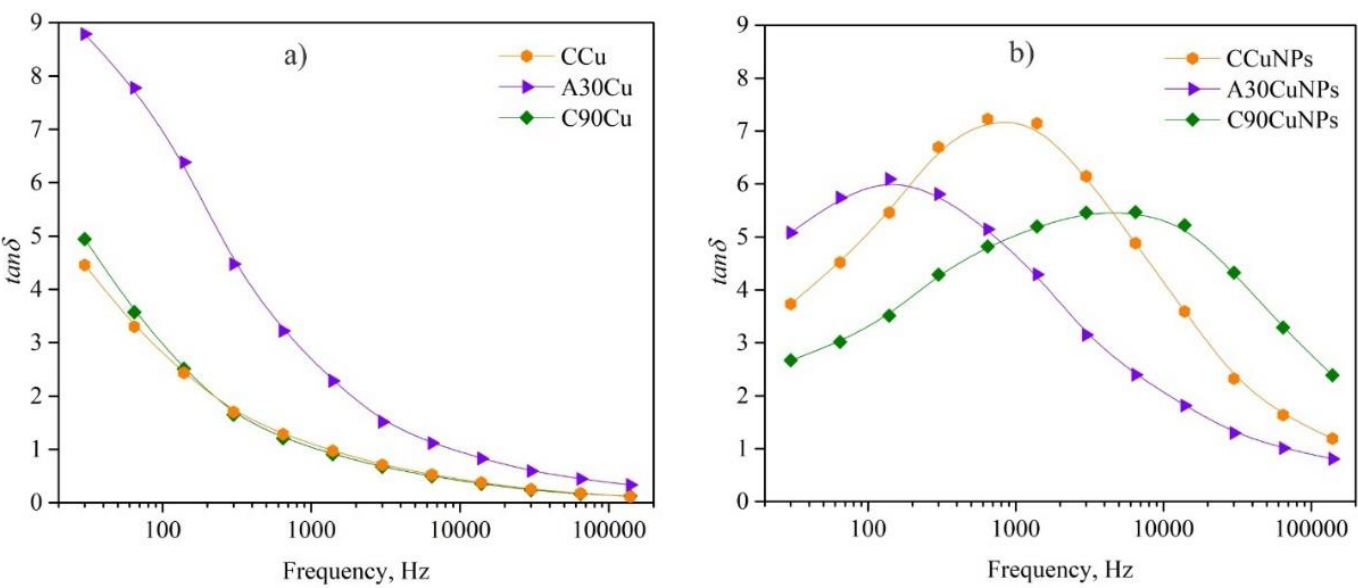

$450 \quad$ Fig. 8 Dielectric loss tangent ( $\tan \delta$ ) of jute fabrics: a) treated with $\mathrm{CuSO}_{4}$ and b) coated with $\mathrm{Cu}$ -

451 based NPs

452 Proposed jute fabrics with excellent effective relative dielectric permeability and a relatively low dielectric loss tangent could be efficiently exploited as energy storage devices, in electrical engineering, electromagnetic protection, flexible electronics, fabric-based electromagnetic shielding devices, etc.

\section{Conclusion}

Alkali and oxidative modifications were utilized as essential tools for investigating the relationship between the jute fibers' structure and their electro-physical properties in a condition of high relative air humidity (i.e., $80 \%$ RH). As a result of chemical modifications, i.e., progressive hemicellulose or lignin removal, the free spaces within/between the fibrils become larger enabling easy movement of structural components' molecules contributing to $38-179 \%$ higher dielectric loss tangent values. and structural parameters. The effective relative dielectric permeability was also enhanced after the chemical modifications due to the removal of non-cellulosic components, increased cellulose content and moisture sorption, and improved accessibility of functional groups. A comparative analysis of differently modified jute fabrics showed that the oxidatively modified fabrics' effective relative dielectric permeability values are higher than that of alkali modified ones which can be attributed to the increased carboxyl group content and the presence of bulk-free water.

To further improve these electro-physical properties, jute fabrics were treated with $\mathrm{CuSO}_{4}$ and $\mathrm{Cu}-$ based nanoparticles were in situ synthesized by reduction of adsorbed $\mathrm{Cu}^{2+}$ ions. Treatment with $\mathrm{CuSO}_{4}$ resulted in up to 5.7 and 6.7 times higher dielectric loss tangent and effective relative dielectric permeability, respectively. Higher content of carboxyl groups present in the jute fabrics provided higher $\mathrm{Cu}^{2+}$ uptake and thus higher total content of $\mathrm{Cu}$ after the reduction. A few single $\mathrm{Cu}$-based nanoparticles (consist of metallic $\mathrm{Cu}$ and $\mathrm{CuO}$ ) were observed across the alkali modified fabric's surface, while single and agglomerated nanoparticles (considered as a mixture of metallic $\mathrm{Cu}$ and both oxides' $\mathrm{CuO}$ and $\mathrm{Cu}_{2} \mathrm{O}$ ) were distributed over the oxidatively modified jute fabric's surface. Independently on Cu-based nanoparticles' structure, moderate to excellent fabric effective relative dielectric permeability is guaranteed. More precisely, during the exploitation in specific conditions contributing to copper reduction, the jute fabrics will be able to store 21 to 163 times more energy from an external electric field than before the exploitation. However, due to the coating with Cu-based nanoparticles, the movement of jute structural components' molecules becomes fabric. 
Developed jute fabrics characterized by high effective relative dielectric permeability and a relatively low dielectric loss tangent could be efficiently utilized in diverse fields including intelligent and electronic textiles, textile capacitive sensors, energy storage devices, electrical engineering, electromagnetic protection, flexible electronics, fabric-based electromagnetic shielding 489 devices, etc.

Acknowledgments

492 The authors thank Dragana Cerovic (The College of Textile Design, Technology and

493 Management, Belgrade) for measuring the fabric electro-physical properties before treatment with

$494 \mathrm{CuSO}_{4}$ and coating with $\mathrm{Cu}$-based nanoparticles, and Biljana Dojcinovic (Institute of Chemistry,

495 Technology and Metallurgy, University of Belgrade) for ICP-OS measurements.

497 References:

498 Agarwal UP, Ralph SA, Baez C, Reiner RS, Verrill SP (2017) Effect of sample moisture content

499 on XRD-estimated cellulose crystallinity index and crystallite size. Cellulose 24:1971-1984.

500 https://doi.org/10.1007/s10570-017-1259-0

501 Ammayappan L, Chakraborty S, Musthafa I, Pan NC (2020) Standardization of a chemical

502 modification protocol for jute fabric reinforcement. J Nat Fibers.

503 https://doi.org/10.1080/15440478.2020.1758276

504 Asanovic K, Cerovic D, Kostic M, Mihailovic T, Ivanovska A (2020) Multipurpose nonwoven

505 viscose/polypropylene fabrics: effect of fabric characteristics and humidity conditions on the

506 volume electrical resistivity and dielectric loss tangent. Fiber Polym 21:2407-2416.

507 https://doi.org/10.1007/s12221-020-1340-4

508 Cerovic DD, Asanovic KA, Maletic SB, Dojcilovic JR (2013) Comparative study of the electrical

509 and structural properties of woven fabrics. Compos Part B Eng 49:65-70.

510 https://doi.org/10.1016/j.compositesb.2013.01.002

511 Dhineshbabu NR, Rajendran V (2016) Antibacterial activity of hybrid chitosan-cupric oxide

512 nanoparticles on cotton fabric. IET Nanobiotechnol 10:13-19. https://doi.org/10.1049/iet-

513 nbt.2014.0073

514 Dube ST, Moutloali RM, Malinga SP (2020) Hyperbranched polyethyleneimine/multi-walled

515 carbon nanotubes polyethersulfone membrane incorporated with $\mathrm{Fe}-\mathrm{Cu}$ bimetallic nanoparticles

516 for water treatment. J Environ Chem Eng 8:103962. https://doi.org/10.1016/j.jece.2020.103962

517 Einfeldt J, Meißner D, Kwasniewski A (2001) Polymer dynamics of cellulose and other

518 polysaccharides in solid state-secondary dielectric relaxation processes. Prog Polym Sci 26:1419-

519 1472. https://doi.org/10.1016/S0079-6700(01)00020-X

520 Emam HE, Manian AP, Široká B et al (2014) Copper(I) oxide surface modified cellulose fibers-

521 synthesis, characterization and antimicrobial properties. Surf Coat Technol 254:344-351.

522 https://doi.org/10.1016/j.surfcoat.2014.06.036 
fibers for sustainable functional biomaterials. Mater Chem Phys 229:174-182.

525 https://doi.org/10.1016/j.matchemphys.2019.02.095

526 French AD (2014) Idealized powder diffraction patterns for cellulose polymorphs. Cellulose 21:885-896. https://doi.org/10.1007/s10570-013-0030-4

528 French AD (2020) Increment in evolution of cellulose crystallinity analysis. Cellulose 27:5445-

529 5448. https://doi.org/10.1007/s10570-020-03172-z

530 Gupta MK (2020) Investigations on jute fibre-reinforced polyester composites: Effect of alkali

531 treatment and poly(lactic acid) coating. J Ind Text 49:923-942.

532 https://doi.org/10.1177/1528083718804203

533 Ibrahim NA, Amr A, Eid BM, El-Sayed ZM (2010) Innovative multi-functional treatments of

534 ligno-cellulosic jute fabric. Carbohyd Polym 82:1198-1204.

535 https://doi.org/10.1016/j.carbpol.2010.06.055

536 Ivanovska A, Cerovic D, Maletic S et al (2019a) Influence of the alkali treatment on the sorption

537 and dielectric properties of woven jute fabric. Cellulose 26:5133-5146.

538 https://doi.org/10.1007/s10570-019-02421-0

539 Ivanovska A, Cerovic D, Tadic N et al (2019b) Sorption and dielectric properties of jute woven

540 fabrics: Effect of chemical composition. Ind Crop Prod 140: 111632.

541 https://doi.org/10.1016/j.indcrop.2019.111632

542 Ivanovska A, Asanovic K, Janakoska M et al (2020a) Multifunctional jute fabrics obtained by

543 different chemical modifications. Cellulose 27:8485-8502. https://doi.org/10.1007/s10570-020-

544 03360-x

545 Khan GMA, Shaikh H, Alam MS, Gafur MA, Al-Zahrani SM (2015) Effect of chemical

546 treatments on the physical properties of non-woven jute/PLA biocomposites. BioResources

547 10:7386-7404. https://doi.org/10.15376/biores.10.4.7386-7404

548 Li P, Tao Y, Shi Q (2014) Effect of fiber content and temperature on the dielectric properties of

549 kenaf fiber-filled rigid polyurethane foam. BioResources 9:2681-2688.

550 https://doi.org/10.15376/biores.9.2.2681-2688

551 Loran S, Chen S, Botton GA et al (2019) The physicochemical characterization of the $\mathrm{Cu}$

552 nanoparticle surface, and of its evolution on atmospheric exposure: application to antimicrobial

553 bandages for wound dressings. Appl Surf Sci 473:25-30.

554 https://doi.org/10.1016/j.apsusc.2018.12.149

555 Loss C, Gonçalves R, Pinho P (2020) A review of methods for the electromagnetic

556 characterization of textile materials for the development of wearable antennas. In: Carvalho NB

557 and Georgiadis A (eds) Wireless power transmission for sustainable electronics, 1st edn. Wiley,

558 New York, pp. 27-56

559 Marković D, Korica M, Kostić M et al (2018a) In situ synthesis of $\mathrm{Cu} / \mathrm{Cu}_{2} \mathrm{O}$ nanoparticles on the

560 TEMPO oxidized cotton fabrics. Cellulose 25:829-841. https://doi.org/10.1007/s10570-017-1566-

5615 
562 Marković D, Deeks C, Nunney T et al (2018b) Antibacterial activity of Cu-based nanoparticles

563 synthesized on the cotton fabrics previously modified with polycarboxylic acids. Carbohyd Polym

564 200:173-183. https://doi.org/10.1016/j.carbpol.2018.08.001

565 Marković D, Ašanin J, Nunney T et al (2019) Broad spectrum of antimicrobial activity of cotton

566 fabric modified with oxalic acid and $\mathrm{CuO} / \mathrm{Cu}_{2} \mathrm{O}$ nanoparticles. Fiber Polym 11:2317-2325.

567 https://doi.org/10.1007/s12221-019-9131-5

568 Marković D, Vasiljević J, Ašanin J et al (2020) The influence of coating with aminopropyl

569 triethoxysilane and $\mathrm{CuO} / \mathrm{Cu}_{2} \mathrm{O}$ nanoparticles on antimicrobial activity of cotton fabrics under dark

570 conditions. J Appl Polym Sci 137:49194. https://doi.org/10.1002/app.49194

571 Montazer M, Dastjerdi M, Azdaloo M, Rad MM (2015) Simultaneous synthesis and fabrication of

572 nano $\mathrm{Cu}_{2} \mathrm{O}$ on cellulose fabric using copper sulfate and glucose in alkali media producing safe bio-

573 and photoactive textiles without color change. Cellulose 22:4049-4064.

574 https://doi.org/10.1007/s10570-015-0764-2

575 Morton WE, Hearle JWS (2008) Physical properties of textile fibres. Woodhead Publishing in

576 Textiles, Cambridge

577 Norimoto M, Yamada T (1970) The dielectric properties of wood IV: On the dielectric dispersion

578 of oven-dried wood. Wood Research : bulletin of the Wood Research Institute Kyoto University

$579 \quad 50: 36-49$

580 Praskalo J, Kostic M, Potthast A et al (2009) Sorption properties of TEMPO-oxidized natural and

581 man-made cellulose fibers. Carbohyd Polym 77:791-798.

582 https://doi.org/10.1016/j.carbpol.2009.02.028

583 Rajini N, Jappes JTW, Rajakarunakaran S, Bennet MPC (2013) Influence of MMT nanoclay on

584 impedance spectroscopy analysis of naturally woven coconut sheath/polyester hybrid composite. J

585 Apply Polym Sci 129:3746-3756. https://doi.org/10.1002/app.39149

586 Rezaie AB, Montazer M, Rad MM (2017) Biosynthesis of nano cupric oxide on cotton using

587 Seidlitzia rosmarinus ashes utilizing bio, photo, sensing and leaching properties. Carbohyd Polym

588 177:1-12. https://doi.org/10.1016/j.carbpol.2017.08.053

589 Samanta AK, Mukhopadhyay A, Ghoshet SK (2020) Processing of jute fibres and its applications.

590 In: Kozłowski RM Mackiewicz-Talarczyk M (eds) Handbook of Natural fibers, Vol. 2: Processing

591 and Applications, 2nd edn. Woodhead Publishing, Cambridge, pp. 49-120

592 Saukkonen E, Lyytikäinen K, Backfolk K et al (2015) Effect of the carbohydrate composition of

593 bleached kraft pulp on the dielectric and electrical properties of paper. Cellulose 22:1003-1017.

594 https://doi.org/10.1007/s10570-015-0556-8

595 Simula S (1999) Electrical and thermal properties of paper. Dissertation, Oy Keskuslaboratori-

596 Centrallaboratorium Ab.

597 Wang X, Chang L, Shi X, Wang L (2019) Effect of hot-alkali treatment on the structure

598 composition of jute fabrics and mechanical properties of laminated composites. Materials 12:1-13.

599 https://doi.org/10.3390/ma12091386 
600 Yang J, Xu H, Zhang L et al (2017) Lasting superhydrophobicity and antibacterial activity of Cu 601 nanoparticles immobilized on the surface of dopamine modified cotton fabrics. Surf Coat Technol 602 309:149-154. https://doi.org/10.1016/j.surfcoat.2016.11.058

603 Yang T, Zhou H, Ma E, Wang J (2018) Effects of removal of different chemical components on 604 moisture sorption property of Populus euramericana Cv. under dynamic hygrothermal conditions. 605 Results Phys 10:61-68. https://doi.org/10.1016/j.rinp.2018.05.024

606 Yue Y, Han J, Han G et al (2015) Characterization of cellulose I/II hybrid fiber isolated from 607 energycane bagasse during the delignification process: Morphology, crystallinity and percentage 608 estimation. Carbohyd Polym 133:438-447. https://doi.org/10.1016/j.carbpol.2015.07.058 609 
Figures

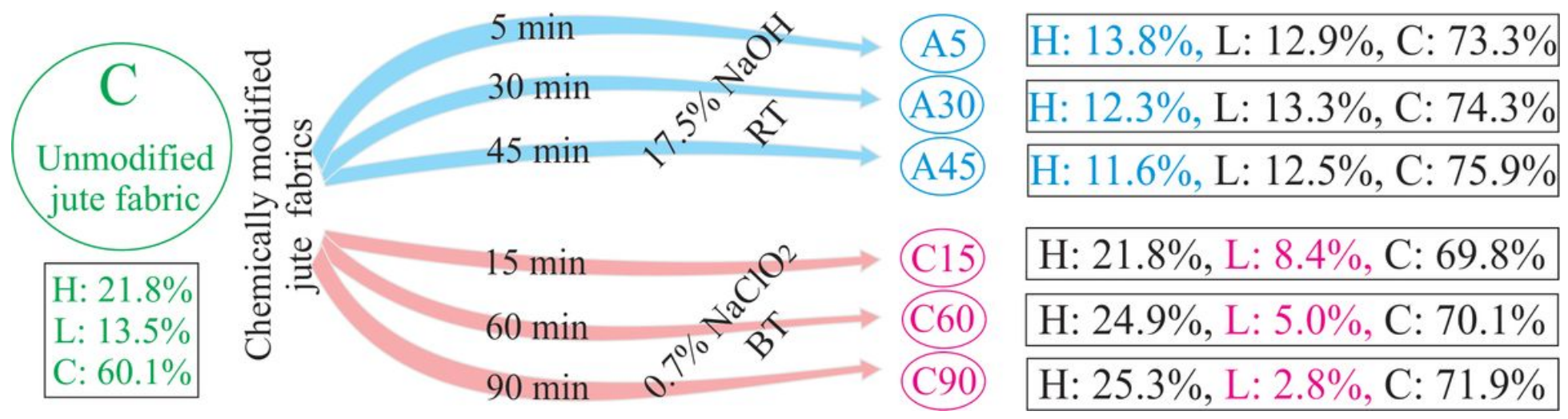

Figure 1

Raw jute fabric chemical modification conditions, fabrics' abbreviations, and chemical compositions ( $\mathrm{H}$ hemicelluloses, L - lignin, C - cellulose)
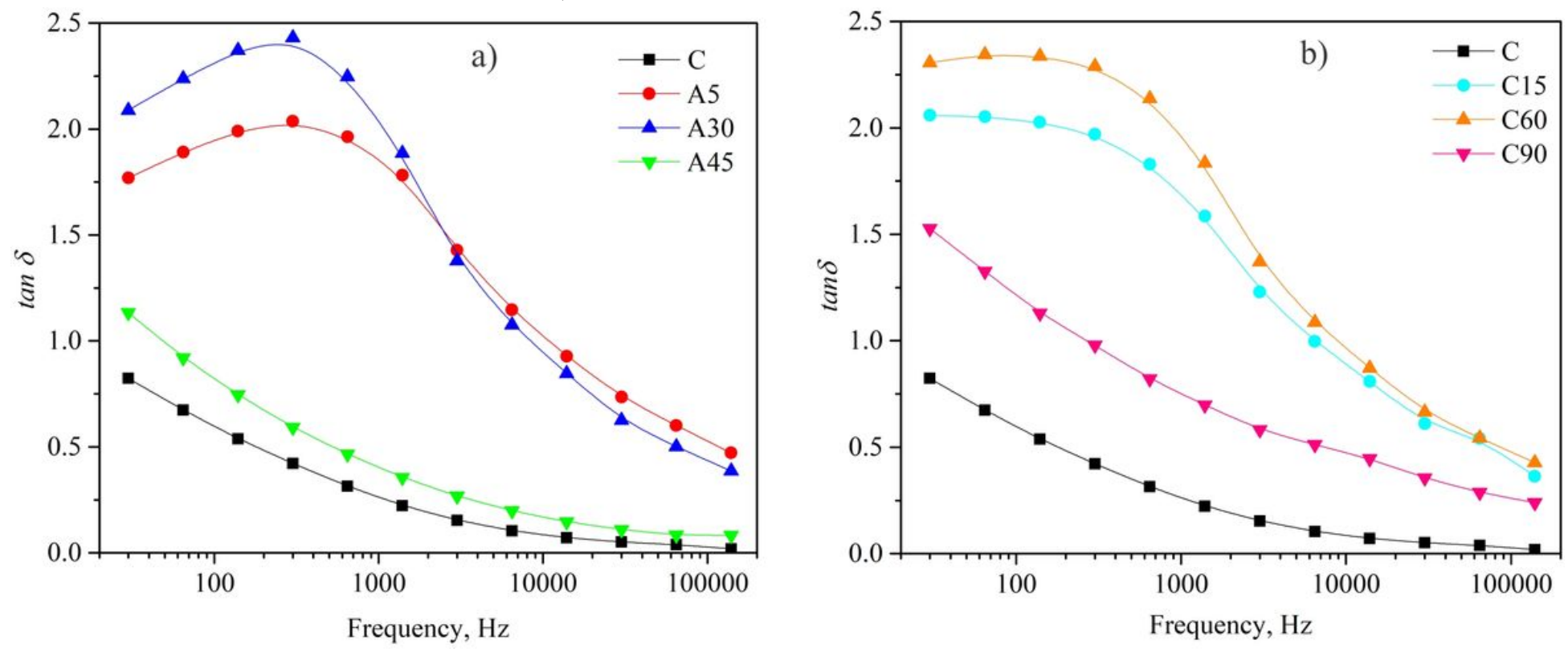

Figure 2

Dielectric loss tangent (tan $\delta$ ) of unmodified and: a) alkali and b) oxidatively modified jute fabrics 

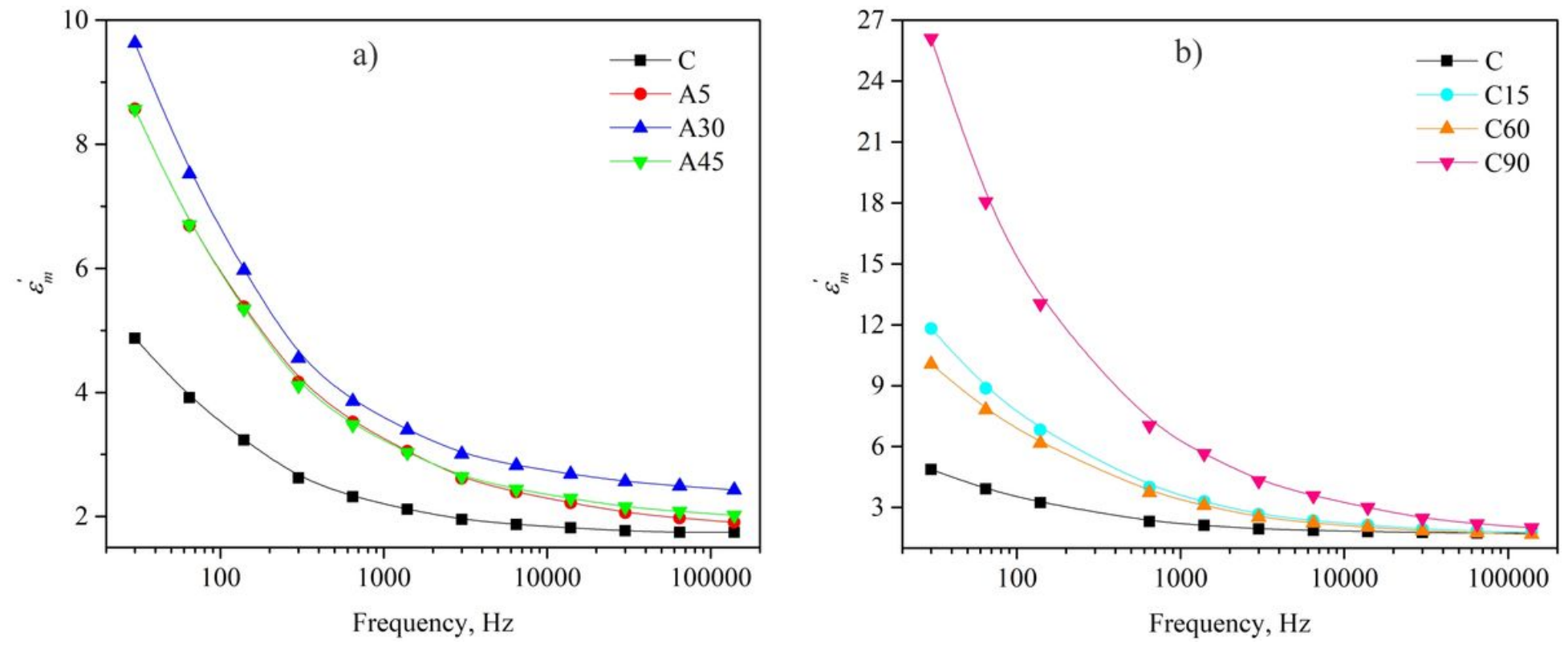

Figure 3

Effective relative dielectric permeability $\left(\varepsilon^{\prime} m^{\wedge \prime}\right)$ of unmodified and: a) alkali and b) oxidatively modified jute fabrics 


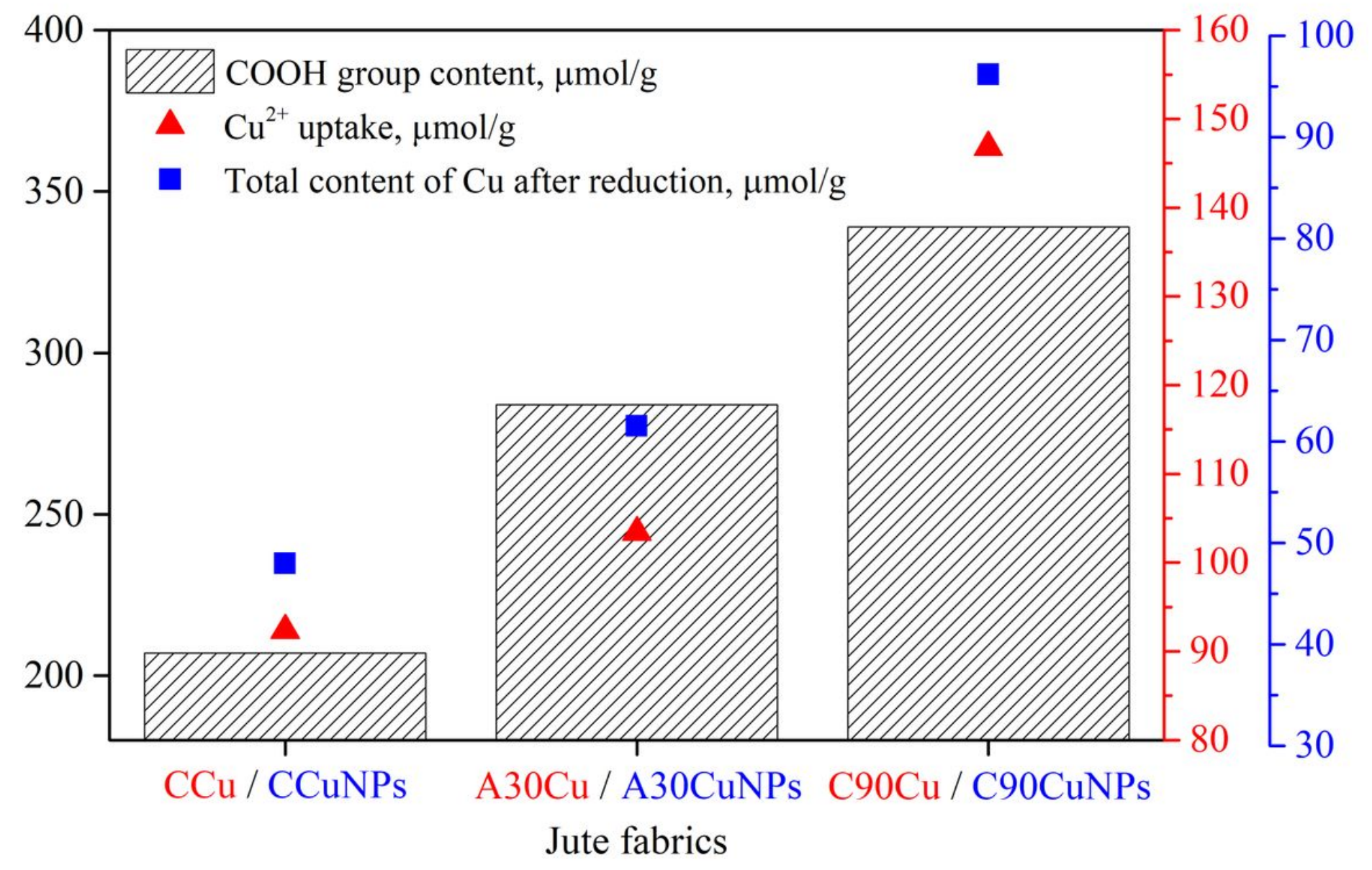

Figure 4

Relationship between $\mathrm{COOH}$ group content, $\mathrm{Cu} 2+$ uptake, and total content of $\mathrm{Cu}$ after reduction in the selected jute fabrics 

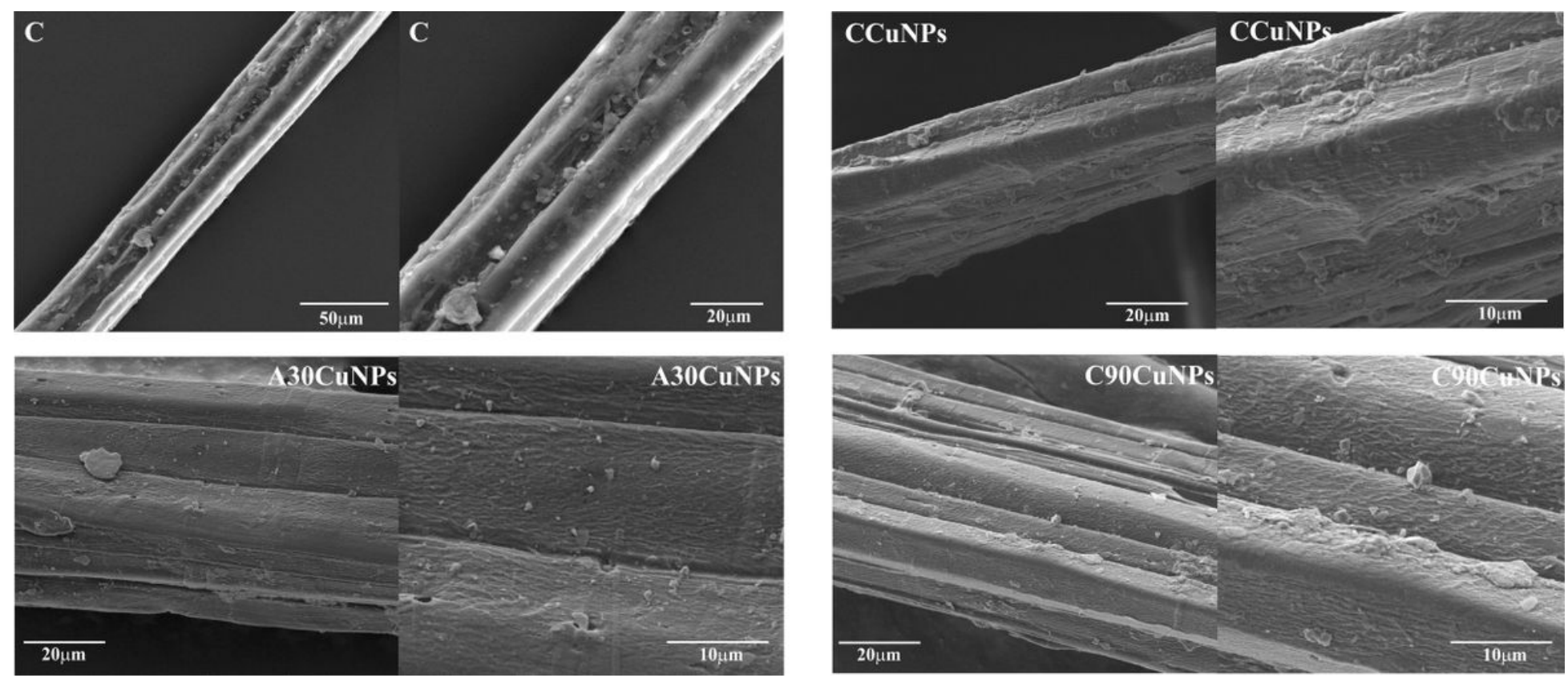

Figure 5

SEM photographs of untreated jute fibers (C), and fibers coated with Cu-based NPs (CCuNPs, A30CuNPs, C90CuNPs) 

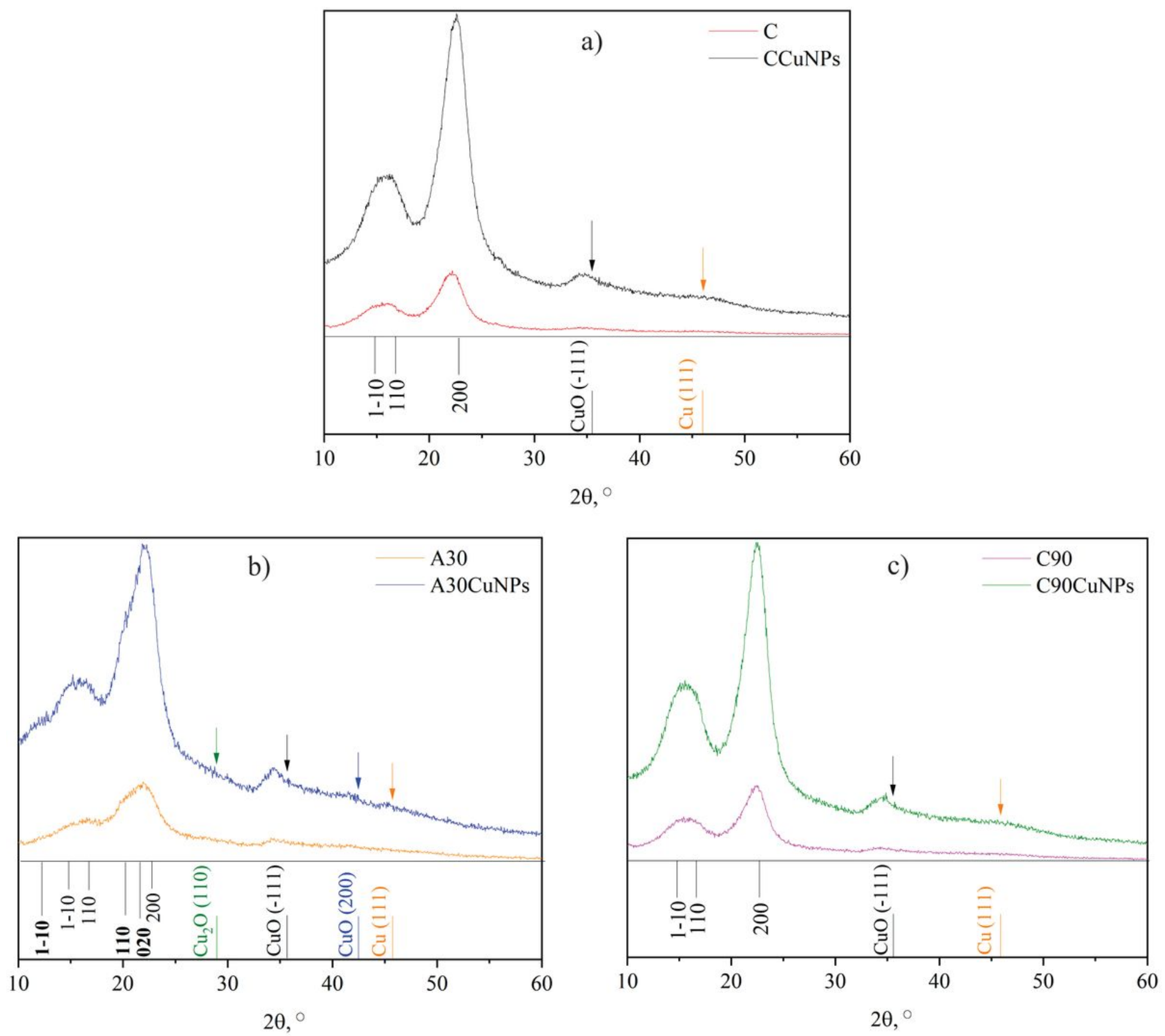

Figure 6

X-ray diffraction patterns of jute fabrics before and after in situ synthesis of Cu-based NPs 

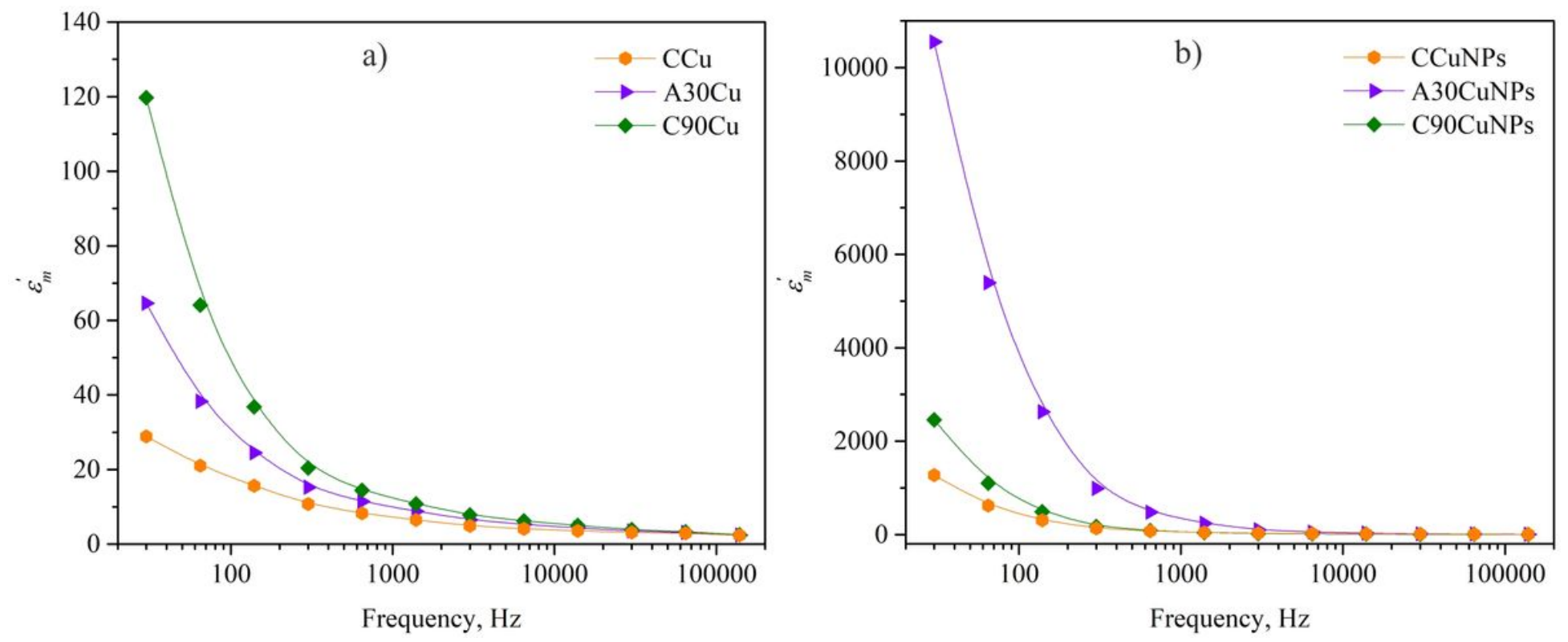

Figure 7

Effective relative dielectric permeability $\left(\varepsilon^{\prime} \mathrm{m}^{\wedge}\right)$ of jute fabrics: a) treated with CuSO4 and b) coated with Cu-based NPs
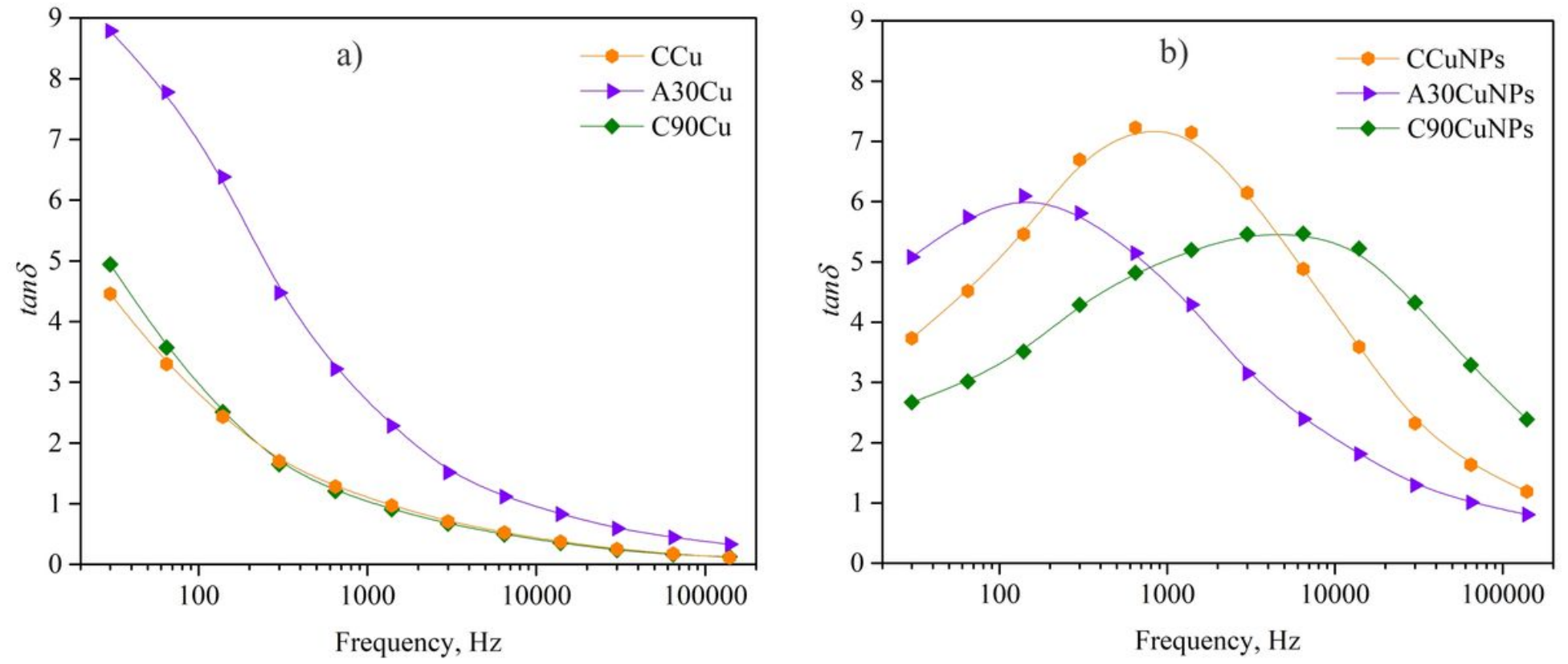

Figure 8

Dielectric loss tangent (tan $\delta$ ) of jute fabrics: a) treated with CuSO4 and b) coated with Cu-based NPs

\section{Supplementary Files}

This is a list of supplementary files associated with this preprint. Click to download.

- GraphicalAbstract.jpg 